\title{
FASZINIERENDE BAUMA
}

\section{FASCINATING BAUMA}

Dear Reader,

bauma 2013 is certain to be exciting. Not only because of the technical trends and new products, but above all because of the mood in the construction machinery and construction vehicle industry. Will 2013 be a good year, or are we heading for hard times?

Most of the reports in this issue are dedicated to new products and trends in mobile construction machines and construction vehicles. For example, Professor Kunze from TU Dresden analyses the most important developments and research in the field of construction machinery. He draws the conclusion that issues of energy, pollutants, mechatronics and simulation will be the main areas of focus at bauma. He is expecting to see "various new products and genuine innovations, many of which come from Germany and which will have a global impact".

But a view towards Asia also remains exciting, and keeping Asia in mind is an essential task for European manufacturers. For example, according to Dr. Marko Dekena, AVL, "there were already forecasts in 2007 that, in 2010, every second construction machine worldwide will be built in China". Speaking in an interview with ATZoffhighway, he says he is particularly curious "to see to what extent Chinese manufacturers will be there this time". Elektronik vollständig neu zusammengeführt werden. Die technischen Hauptaspekte werden anhand des MAN TGS als Plattform für Allradfahrzeuge erklärt.

Ihr

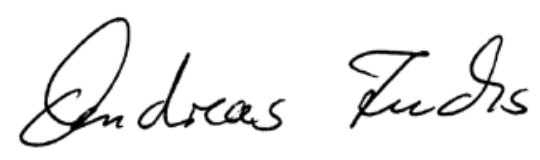

ANDREAS FUCHS, Chefkorrespondent Hochheim (Main), 4. März 2013

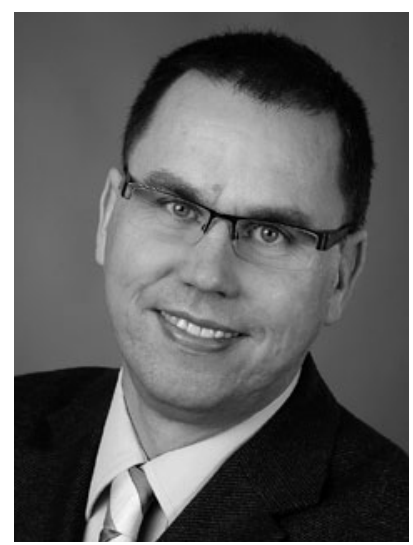

But it is not only in the field of construction machinery that a large number of innovations will be presented this year but also in construction vehicles. 2014 is an important date with regard to exhaust emissions. For that reason, Mercedes-Benz is successively renewing its entire commercial vehicle product portfolio in order to offer all customers a Euro VI-compliant vehicle for long-distance transport, heavy distribution and construction applications by 2014. At the end of January, the new Arocs series of heavy-duty construction vehicles was presented to the public. The Tognum Group will also offer newly developed engines that meet the Stage IV and Tier 4 final off-road emissions standards for construction and special machines as well as agricultural and forestry machinery from 2014. You can read all about the technical innovations in this issue. And last but not least, MAN will also be unveiling a new truck generation at bauma that will comply with the Euro VI emissions standard. Meeting this standard required an entirely new configuration of engine technology, exhaust aftertreatment and complete vehicle electronics. The main technical aspects are explained on the basis of the MAN TGS as a platform for all-wheel-drive vehicles.

ANDREAS FUCHS, Chief Correspondent Hochheim (Main), 4 March 2013 